\title{
The Impact of Different FDI Entry Modes on Economic Growth in Asia
}

\author{
L. Wu and H. Xie
}

\begin{abstract}
Greenfield investment and cross-border M\&A are two main FDI entry mode, different FDI entry mode on the economic growth of host country are different in literatures. In particular, some opinions suggest that the impact of cross-border M\&A can promote economic growth in the countries that have Sound market and a stable institutional environment, and this relationship is not suitable for those developing countries. This paper examines the data from 11 countries in Asia between 2009 and 2015, the empirical results show that this conclusion cannot be supported either in developed or developing countries, the impact of cross-border M\&A on the growth rate of GDP is not significant. This means that the countries in Asian region show a greater diversity in geopolitical, economic development, industry distribution, financial capital, etc. as the most active country in the Asian M\&A market and the advocate for the Belt and Road Initiatives, china should further strengthen supervision and make industry guidance for future investment in Asia, so that both the acquirer and the target countries could benefit from it.
\end{abstract}

Index Terms -FDI, FDI entry mode, economic growth, Asia.

\section{INTRODUCTION}

At present, China is encouraging enterprises to enter international market by "bring in" and "go global" strategy. The strategic change from international trade to international direct investment not only builds the international economic system of China, but also promotes the rational allocation of production factors like capital, human resources, technology in the world, stimulating economic growth. In this situation, the foreign direct investment (FDI) and foreign trade of china developed rapidly, in 2015 the net outward foreign direct investment of china was 145.667 billion dollars, among them, from the aspect of regional distribution, Asia is the most concentrated area of China's investment activity, the net investment of China to Asian countries was 108.371billion dollars, accounting for more than $70 \%$ of the total. China has set up more than half of all foreign enterprises in the Asian countries or regions, the enterprises are mainly located in Hong Kong, Vietnam, Japan, United Arab Emirates, Singapore, Korea, Thailand, Indonesia, Saudi Arabia, etc. the relationship between china's FDI and economic growth has become a matter of concern. For a long time, domestic scholars have made more studies on China's inward FDI and domestic economic growth, there is not much research on the

Manuscript received January 16, 2018; revised March 10, 2018. This work was supported in part by the Social Science General Program of Beijing Municipal Education Commission (SM201710005004).

$\mathrm{L}$. Wu is with the School of Economics and Management, Beijing University of Technology, China (e-mail: wulong@ @jut.edu.cn).

Hui Xie is with the Pilot College, Beijing University of Technology, China (e-mail: sherry_xie1@163.com). effect of China's outward FDI to host countries' economic, especially to Asian countries or regions. Since many countries have an ambiguous attitude to FDI from other countries, the study of economic impact of China's direct investment on Asian countries has much theoretical and practical significance. Not only can clarifying whether China's direct investment to Asia is complementary or threatening, enrich the research in this field, but also can help Chinese enterprises adjusting the investment field according to the economic effects of different countries, making oversea investment more effective.

\section{LITERATURE REVIEW}

The entry modes of FDI into the host countries mainly includes greenfield investment and cross-border mergers and acquisitions (M\&A), greenfield investment, also known as new investment or create investment, refers to the investment mode that investors establish new factory or subsidiary in the host country, and cross-border M\&A means that investors acquire the original enterprise in host country. The impact of FDI on economic growth of host country has been concerned in recent years. The earlier scholars have two opposite views on this relationship. One is that FDI has a positive effect on economic growth of host country. Chenery, Bruno and Mckinnon (1962) proposed "Two gap" theory, have demonstrated that the inflow capital from abroad can contribute the economic growth of developing countries. The main idea of this theory is that developing countries have a gap between the amount of resources needed to achieve their economic developing goals and the largest domestic supply, and the introduction of external resources is a necessary condition to make up for these gaps, to be exactly, the foreign capital inflows could make up for the "gap of foreign currency" and the "gap of saving", which can improve the level of domestic investment and introduce the capital goods that could not be produced by developing countries, thus promote economic growth rate. The endogenous growth theory also supports the proposition that FDI can lead to long-term economic growth of host countries, capital flows can lead to technological diffusion and the delivery process of advanced science, technology, knowledge and human capital around the world, leading to "economic convergence" between developing and developed countries and promote economic growth. The externalities of FDI have an impact on long-term economic growth. Accordingly, for a single enterprise, with the accumulation of capital, the marginal output of capital diminishes, then it cause diminishing returns. The existence of externalities is the key to the difference between the firm and the social investment rate of return, it 
curbs the decline of capital marginal output. Another point of view is that FDI has no or negative impact on the economy of host countries. Stoker (1999) argued that the effect of FDI to economic growth is based on a stringent assumptions, it does not exist in reality. From the point of "crowding out effect" of investment, FDI would crowd out domestic investment, increasing external vulnerability, and causing dependence, thus negatively affecting the host country's economy [1]. In recent years, with the refinement of the study, more scholars have the view of conditions promoting, that the promotion of FDI to economic growth is based on a series on conditions, the effects may have a great difference according to the financial market [2], [3], the lever of labor [4], etc. Neto et al. first suggests that the difference of FDI entry mode is an important reason for the difference of the relationship of FDI and economic growth of host country [5]. Then many scholars propose some similar view, widely agreed greenfield investment can promote the economic growth of host country, but the impact of cross-border M\&A has no common result. Kim et al. hold that cross-border M\&A can only meet the need of profit maximization of multinational companies, for the host country the impact is only to change the owner of the merged enterprises without increasing the total amount of domestic investment. The empirical study of Wang et al. shows that cross-border M\&A are generally negatively related to economic growth of host country, only when the human resources level of host country reaches a certain height will appear a weak positive correlation.

The paper of Neto et al. [5] also mentioned that different percentage of two FDI entry modes in the sample would cause different statistical results. Therefore, selecting differ countries as sample in each paper would lead to different conclusions. Li et al. [6] use the data of global 137 countries and regions as sample, it shows that cross-border M\&A can promote the economic growth of host country in sound financial system and stable institutional environment, or can be seen as in developed countries, but for developing countries, because the financial system is not perfect and the institutional environment is unstable, only greenfield investment can promote economic growth. The similar analysis method have also been used in Eurozone countries [7]. In resent years, with the implementation of the strategy of the Belt and Road Initiatives and the build of Asian Infrastructure Investment Bank, China has been expanding its investment to foreign countries, especially Asian countries or regions. Analyzing the impact of China's foreign investment on Asian countries' economic growth, can provides strategy basis for China government to promote "go global" strategy. Therefore, based on the thinking and method of the literature of $\mathrm{Li}$ et al. this paper chooses the data of 11 representative Asian countries or regions from 2009 to 2015 to make an empirical analysis.

\section{EMPIRICAL ANALYSIS}

\section{A. Model and Variables}

Many empirical paper on the relationship between FDI and economic growth is based on Solow macroeconomic growth model, according to the method of $\mathrm{Li}$ et al. for macroeconomic growth model:

$$
P(t)=A(t) F(K(t), L(t))
$$

Introducing fully differential and using log function, obtaining a linear model:

$$
\ln \dot{P}=\ln \dot{A}+S_{K} \ln \dot{K}+S_{L} \ln \dot{L}
$$

Using logarithmic data of real GDP will include the exchange rate fluctuation, which may impact the accuracy of data, imitating the practice of similar research paper, so we use GDP growth rate as the dependent variable, this data has been collected from UN Conference on Trade and Development (UNCTAD) database, it is the real growth rate valuated by domestic currency of each country and have been excluded the inflation factors, it can explain the economic growth of host country more accurately than simply using total GDP, and as can be seen in the equation below:

$$
\begin{aligned}
\ln G \dot{D} P & \approx \ln \left[G D P_{n}(1+\text { Growth })\right]-\ln G D P_{n} \\
& =\ln (1+\text { Growth }) \approx \text { Growth }
\end{aligned}
$$

Therefore, the basic regression model of this paper is:

$$
\text { Growth }=\alpha+\beta X+\gamma C+\varepsilon
$$

where $X$ represents the explanatory variable and $C$ represents the control variable.

The explanatory variable $X$ includes total amount of greenfield investment Green and $M \& A$ in each year in the territory, which are similar to GDP data using its growth rate. The control variable $\mathrm{C}$ is the same as the paper of Li et al. [6]. including the gross domestic product $g d p$ to control the difference of big country and small country; the gross domestic product per capita of host country $g d p p c$ to control the difference in the level of economic development; the host country's population growth rate pop to control the increase of economic growth caused by the increase in labor supply; the opening up index open to control the degree of one country opening to the outside world, using the percentage of export to GDP as the opening up index; the net export growth rate nexp to control the economic growth caused by the increase of exports.

To sum up, the regression model is built as follows:

$$
\begin{aligned}
& \text { growth }=\alpha+\beta \text { Green }+\gamma_{1} g d p+\gamma_{2} g d p p c \\
& +\gamma_{3} \text { pop }+\gamma_{4} \text { open }+\gamma_{5} \text { nexp }+\varepsilon \\
& \text { growth }=\alpha+\beta M \& A+\gamma_{1} g d p+\gamma_{2} g d p p c \\
& +\gamma_{3} \text { pop }+\gamma_{4} \text { open }+\gamma_{5} \text { nexp }+\varepsilon
\end{aligned}
$$

\section{B. Data Sources}

The data of this paper is from the UNCTAD Data Center, data of greenfield investment is obtained by the subtraction of M\&A form FDI. After removing the countries having missing data, the sample of this paper includes 11 countries or regions in 2009-2015, which are China's representative trading partners and investment areas in Asia, among them, developed countries or regions include Japan, south Korea, Singapore, Israel, Hong Kong and Taiwan, developing 
countries include India, Saudi Arabia, Thailand, Turkey and Vietnam.

\section{Panel Estimation}

As the paper of Li et al mentioned, according to the results of Hausman test and the need to control the time trend, we also choose Fixed effects estimation method of both cross-section and period, the results show that it can eliminate the time trend more effectively than adding a time variable, and the regression results are more significant. So we use this method to do panel estimation using full sample, developed country data and developing country data, the results show as follows:

TABLE I: EstimATION RESUlts USING FiXED EFFECTS Methods

\begin{tabular}{|c|c|c|c|c|c|c|c|}
\hline \multirow{3}{*}{$\begin{array}{l}\text { variables } \\
\text { model }\end{array}$} & \multicolumn{6}{|c|}{ Dependent variable: Growth } & \multirow[b]{3}{*}{ (2) } \\
\hline & \multicolumn{2}{|c|}{ Full data } & \multicolumn{2}{|c|}{ Developed country } & \multicolumn{2}{|c|}{ Developing country } & \\
\hline & & (1) & $(2)$ & $(1)$ & $(2)$ & $(1)$ & \\
\hline \multirow[t]{2}{*}{ Green } & & $0.1200^{*}$ & & $0.1189 *$ & & $1.0235^{* *}$ & \\
\hline & $(1.88)$ & & $(2.23)$ & & $(2.51)$ & & \\
\hline \multirow[t]{2}{*}{$\mathrm{M} \& \mathrm{~A}$} & & & \multicolumn{2}{|c|}{-0.0679} & \multicolumn{2}{|c|}{0.0040} & -0.0758 \\
\hline & \multicolumn{2}{|r|}{$(-1.05)$} & \multicolumn{2}{|c|}{$(0.03)$} & \multicolumn{2}{|c|}{$(-0.83)$} & \\
\hline \multirow[t]{2}{*}{ GDP } & & -0.0000 & -0.0000 & 0.0000 & \multicolumn{2}{|c|}{$0.0000 \quad 0.0000$} & -0.0000 \\
\hline & $(-0.28)$ & $(-0.69)$ & $(0.98)$ & $(0.44)$ & $(0.01)$ & $(-0.02)$ & \\
\hline \multirow{2}{*}{ GDPpC } & & 0.0001 & 0.0001 & -0.0001 & -0.0001 & $0.0009 * *$ & $0.0009 *$ \\
\hline & $(0.93)$ & $(0.90)$ & $(-1.11)$ & $(-0.89)$ & \multicolumn{2}{|c|}{$(2.62) \quad(2.09)$} & \\
\hline \multirow[t]{2}{*}{ Pop } & & 232.56 & $4 \quad 255.602$ & $2 \quad 182.976$ & $6 \quad 226.585$ & $5 \quad 783.623$ & 842.532 \\
\hline & $(1.12)$ & $(1.20)$ & $(0.80)$ & $(0.90)$ & \multicolumn{2}{|c|}{$(1.58) \quad(1.48)$} & \\
\hline \multirow[t]{2}{*}{ Open } & & 2.5246 & 1.9511 & 2.3507 & 1.3289 & -0.1071 & -0.5333 \\
\hline & $(1.00)$ & $(0.76)$ & $(0.90)$ & $(0.47)$ & $(-0.02)$ & $(-0.07)$ & \\
\hline \multirow[t]{2}{*}{ NExp } & & $6.733^{*}$ & 5.627 & $17.501 *$ & $* * \quad 12.495 *$ & $\quad 3.031$ & 3.148 \\
\hline & $(1.92)$ & (1.59) & $(2.60)$ & $(1.76)$ & \multicolumn{2}{|c|}{$(0.58) \quad(0.53)$} & \\
\hline Countries & & 11 & 11 & 6 & 6 & 5 & 5 \\
\hline Obs & & 77 & 77 & 42 & 42 & 35 & 35 \\
\hline F-value & & 7.23 & 6.92 & 10.40 & 8.38 & 3.70 & 2.59 \\
\hline Prob $>F$ & & 0.0000 & 0.0000 & 0.0000 & 0.0000 & 0.0045 & 0.0275 \\
\hline
\end{tabular}

For all three samples, in the result of model (1), coefficient of Green is positive and significant, undoubtedly the impact of greenfield investment on economic growth is positive, greenfield investment increases the total investment in host country through building new enterprises and factories, etc. so it can promote economic growth. For model (2), the coefficient of M\&A is not significant, whether it use full sample, the developed country or the developing country sample, that is, there is no evidence shows that cross-border M\&A can positively impact the economic growth of host countries, this result is inconsistent with the result of literature using 173 countries or regions. Many studies have shown that in developed countries, because of the sound financial market and the stable institutional environment, the cross-border M\&A can be converted into the endogenous investment of host country through reinvestment process, thus promote economic growth. Why the data of Asian countries or regions did not shows this feature? There need to further analyze the reasons from original data.

\section{A. Result Discussion}

The results of regression model are influenced by the difference of sample and the choice of control variables, therefore, the conclusion that effect of cross-border M\&A on economic growth is not significant in the regression results should be further discussed, from the aspect of each country's practice of M\&A and industry distribution, model setting and so on.

Since 2014, there has been a wave of mergers and acquisitions in Asia, the number of Asian M\&A in 2015 reached a record high level, but it need to pay attention to two aspects, one is that there can be seen from figure 1 and 2 , in
2008-2016 the amount and number of M\&A in Asia show a great volatility, the sample of 11 countries or regions selected by this paper shows the same trend. The transaction amount and number of M\&A would be affected by many uncertainties in the world, such as geopolitical changes, regulation becoming increasingly stringent and so on, and the percentage of China in deals of Asian M\&A is relatively large, so it is also related to China's economic downward pressure. Therefore, the relationship between cross-border M\&A and economic growth includes many intermediate factors, which cause inconsistent trends of two variables.

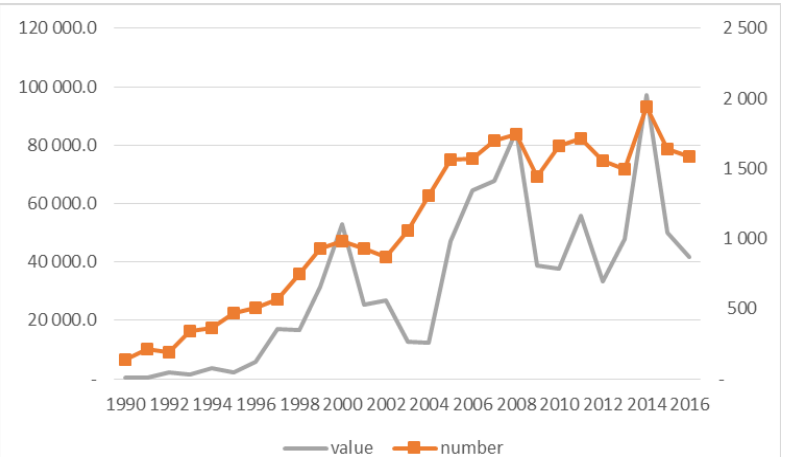

Fig. 1. Number and value of cross-border M\&As of seller in Asia.

Second, behind the buoyant market of Asian M\&A, there should also be noted that, referring to some report of survey institutions (such as Brunswick Consulting), China's future M\&A target market will be Asia, but in recent years the largest amount of M\&A deals occurred outside of China and Asia regions. For example China National Chemical Corporation acquired Syngenta in Switzerland with \$43.2 billion, Bohai Capital took over the commercial aircraft 
leasing business of American CIT with $\$ 10$ billion, and China Investment Co acquired Australian Asciano Ltd with \$6.7 billion and so on. From the country distribution of seller of cross-border M\&A in 2016, as shown in Fig. 3, Europe accounted for $85 \%$ of the total amount, while only $9 \%$ in Asia, the industry distribution is concentrated in services such as financial, retail and real estate, etc. As the largest M\&A buyer in Asia, Chinese enterprises want to acquire technology, intellectual property and so on from M\&A deals. For the host country, as the seller of M\&A, some studies show that when capital of host country tends to flow out, it may disrupt the reinvestment process, which is an important path of M\&A impacting on economic growth of host country. Therefore, in Asia the impact of cross-border M\&A on economic growth of countries with the role of acquirer or buyer, may be greater than the impact of it on the host country's economic growth.

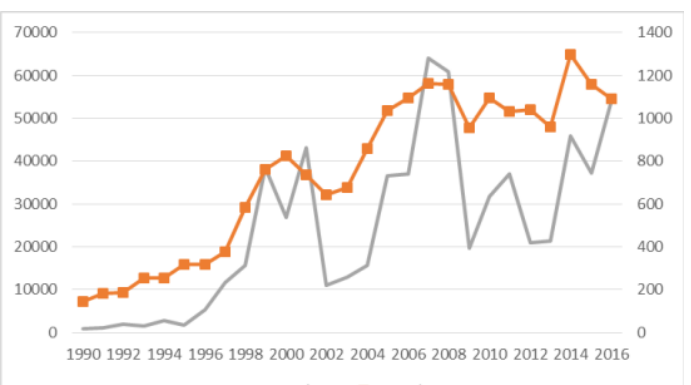

Fig. 2. Number and value of cross-border M\&As of seller in 11 countries/regions.

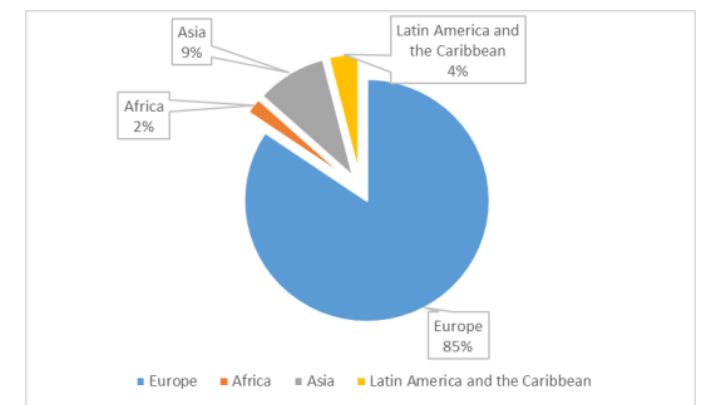

Fig. 3. Percentage of total cross-border M\&As' value by region of seller in 2016.

In addition, it should be noted that in each Asian country of seller, the total value of cross-border M\&As vary widely, the regression model may lose a certain critical control variables, for example, many studies suggest that FDI can promote economic growth then the host country has enough high level labor [8], in this paper we only use the population representing the supply of labor, so one of the focus of further study could be the specific path of the impact of cross-border M\&A on economic growth.

\section{CONCLUSIONS}

For the question of whether FDI can promote the economic growth of host country, there have been widely recognized that greenfield investment has a positive impact on economic growth since it provides foreign financial resources to increase the capital stock of host country. But the impact of cross-border M\&A on economic growth is affected by many factors. Some empirical studies using 137 countries or regions in the world as sample, show that cross-border M\&A can promote economic growth of developed countries through the transformation of endogenous investment, because these countries' financial markets are sound and institutional environment are stable. But in this paper, we found that this conclusion is not suitable for Asian countries or regions, getting the opposite result when using 11 countries or regions in Asia to do the empirical analysis, the impact of cross-border M\&A on GDP growth rate is not significant for both developed and developing countries. It means that Asian countries and regions, as the most attractive area of M\&A activities in recent years, show a greater diversity in geopolitical, economic development, policies and regulations, industry distribution, financial capital, etc. China's strategy of the Belt and Road Initiatives, and the build of Asian Infrastructure Investment Bank, have increase the overseas investment interest to Asian regions, for both outward or inward cross-border investment, Chinese government should further strengthen the control and guidance the investment to certain key industries, to avoid blind investment activities, not only can China access to new technologies and intellectual property, enhance the return on capital, but also can host countries in Asia supplement investment shortage in relevant industries, benefiting both China and Asian countries.

\section{REFERENCES}

[1] B. Aitken and A. Harrison, "Do domestic firms benefit from direct foreign investment? Evidence from Venezuela," American Economic Review, vol. 89, no. 3, pp. 605-618, March 1999.

[2] W. N. W. Azman-Saini, S. H. Law, and A. H. Ahmad, "FDI and economic growth: New evidence on the role of financial markets," Economics Letters, vol. 107, no. 2, pp. 211-213, February 2010.

[3] L. Alfaro, A. Chanda, S. Kalemli-Ozcan et al., "Does foreign direct investment promote growth? Exploring the role of financial markets on linkages," Journal of Development Economics, vol. 91, no. 2, pp. 242-256, February 2010.

[4] M. Wang and M C. Sunny-Wong, "What drives economic growth? The case of cross-border M\&A and greenfield FDI activities," Kyklos, vol 62, no. 2, pp. 316-330, February 2009.

[5] P. Neto, A. Brandao, and A. Cerqueira, "The impact of FDI, cross-border mergers and acquisitions and greenfield investments on economic growth," FEP Working Paper, pp. 1-35, October 2008.

[6] C. Li, S M. Li, C. Philip et al., "Can cross-border M\&As promote economic growth?-Research on FDI entry modes, endogenous investment and economic growth," Management Review, vol. 27, no. 4, pp. 3-12, April 2015.

[7] P. Pegkas, "The impact of FDI on economic growth in Eurozone countries," The Journal of Economic Asymmetries, vol. 12, no. 2, pp. 124-132, February 2015

[8] A. Wijeweera, R. Villano, and B. Dollery, "Economic growth and FDI inflows: A stochastic frontier analysis," The Journal of Developing Areas, vol. 43, no. 2, pp. 143-158, February 2010.

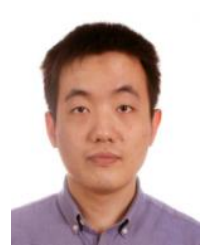

L. Wu was born in Beijing on September 3, 1988. He got doctor degree in Management science and engineering in Beijing University of Technology.

He is currently a lecturer at the school of economics and management, Beijing University of Technology, Beijing, China from 2015. His major research interests are in the fields of policy evaluation, econometrics.

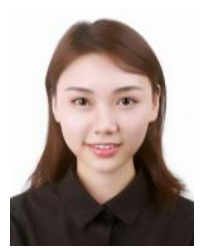

H. Xie was born in Beijing on August 6, 1995. She is currently a student in pilot college in Beijing University of Technology, majoring in international economics and trade. Her major research interests are in cross-border merger and acquisition. 